\title{
As esferas pública e doméstica da hospitalidade na Jornada Mundial da Juventude Rio 2013 na percepção de estrangeiros
}

The pubic and domestic spheres of hospitality on World Youth Day Rio 2013 in the foreigners' perception

\author{
Luciana Thais Villa Gonzalez \\ Universidade Federal Rural do Rio de Janeiro - UFRRJ - Rio de Janeiro - Rio de Janeiro - Brasil
}

\section{Cecília Loreto Mariz}

Universidade do Estado do Rio de Janeiro - UERJ - Rio de Janeiro - Rio de Janeiro - Brasil

\section{Paulo Gracino Junior}

Instituto Universitário de Pesquisas do Rio de Janeiro - IUPERJ - Rio de Janeiro - Rio de Janeiro - Brasil

Resumo: Este artigo tem como objetivo principal apresentar dados relativos a uma pesquisa realizada durante a Jornada Mundial da Juventude Rio 2013 (JMJ Rio 2013) acerca da percepção dos participantes estrangeiros do evento em relação à hospitalidade doméstica e pública ofertadas pela cidade do Rio de Janeiro e sua população. A Igreja Católica carioca promoveu antes e durante o evento a hospedagem de participantes na casa dos habitantes da cidade, bem como, ocupou com diversas atividades as mais variadas regiões do município, usualmente, esquecidas pelos turistas. Desta forma, o bem receber no lar e na cidade tornaram-se aspectos fundamentais da JMJ Rio 2013 para os participantes deste evento. A pesquisa teve caráter quanti-qualitativo uma vez que utilizou como instrumentos de coleta de dados um survey aplicado a 550 participantes estrangeiros inscritos oficialmente no evento durante os seis dias de sua duração e a realização de 17 entrevistas semiestruturadas. Por meio dos dados coletados, percebeu-se que a hospitalidade doméstica deu sentido profundo e significativo a experiência do evento vivida pelos entrevistados e amenizou aspectos considerados negativos por estes em relação a hospitalidade pública.

Palavras-chave: Jornada Mundial da Juventude. Hospitalidade Doméstica. Hospitalidade Pública.

\begin{abstract}
This article's aims to present data collected from a poll taken over World Youth Day Rio 2013 (WYD Rio 2013) about the perception of domestic and public hospitality of the foreigner participants of the event. Catholic Church promoted before and over WYD the reception of the event's participants in the houses of the people of Rio de Janeiro as well as in schools and other public spaces. The event has overtaken all the city reaching places which are forgotten by the tourism market. In this way, welcoming people in homes and city became essential elements of WYD for its participants. The research used a mixed method approach, bringing together qualitative and quantitative data which were collected in a poll applied to 550 foreigners participants officially subscribed with WYD's organization team during the six days of the event. In addition, it is presented as well data from 17 semi-structured interviews. The data analysis show that domestic hospitality has given deep meaning to WYD participant's experience and has diminished the frustration with issues concerning public hospitality.
\end{abstract}

Keywords: World Youth Day. Domestic Hospitality. Public Hospitality. 


\section{Introdução}

A cada dois ou três anos desde 1986, a Igreja Católica promove em algum país do mundo o evento denominado Jornada Mundial da Juventude (JMJ). Com o objetivo de aproximar a Igreja dos jovens, o evento tem na juventude até 30 anos seu foco principal. É considerado o maior evento religioso voltado a este público no mundo $e$ atrai milhares/milhões de participantes (SINGLETON, 2011). A $28^{\circ}$ edição do evento foi realizada na cidade do Rio de Janeiro (RJ)/Brasil no ano de 2013. O número de participantes inscritos oficialmente junto à organização do evento foi de 429 mil pessoas, contudo, algumas atividades da JMJ como as missas campais lideradas pelo Papa Francisco registraram 3,7 milhões de pessoas (MINTUR, 2013). Como o evento possui caráter internacional, havia entre os inscritos 209 mil estrangeiros de 175 países (CNBB, 2013).

É sabido que o público jovem de forma geral não possui fontes de recursos financeiros abundantes para o financiamento de viagens, sobretudo, internacionais. Por estar em uma fase da vida em que a maioria depende dos pais economicamente, a realização de uma viagem ao exterior pode ser bastante complexa. Para minimizar estes fatores e garantir a participação de jovens do mundo todo no evento, a Igreja Católica do país anfitrião da JMJ, incentiva que as famílias católicas ou não da cidade sede hospedem gratuitamente os participantes oficialmente inscritos no evento em suas casas. Apesar de um valor módico ser cobrado dos inscritos pela hospedagem, esta quantia não é repassada às famílias de acolhida, e o montante é usado para custeio da organização geral do evento.

Às famílias de acolhida era solicitado que oferecessem aos participantes - chamados de "peregrinos" -, um espaço dentro de suas casas para que estes pudessem utilizar seus sacos de dormir para descanso e permitissem o uso do banheiro. A Igreja garantia a alimentação dos peregrinos, e, por este motivo, as famílias não precisavam se ocupar com as refeições de seus hóspedes. A hospedagem de peregrinos em espaços como escolas, ginásios e até mesmo empresas privadas também foi incentivada. Desta feita, $166.032^{1}$ inscritos solicitaram hospedagem junto à organização do evento e foram acolhidos e recebidos em casas de famílias e espaços coletivos, o que será considerado neste trabalho como uma forma de hospitalidade doméstica, ao contrário, da hospitalidade pública que é tomada aqui como aquela exercida pela cidade em relação a seus visitantes. Muitos chegaram até duas semanas antes do início do evento, e, outros se foram até duas semanas depois do fim deste, contudo, a hospedagem destes participantes foi garantida pela equipe da JMJ Rio 2013. Assim, parece evidente que a JMJ depende de maneira bastante substancial da hospitalidade doméstica e pública da cidade que a sediará para sua realização e sucesso, o que nos leva na próxima seção a trazer algumas considerações acerca dos conceitos de hospitalidade doméstica e pública para melhor entendimento dos dados que serão posteriormente apresentados.

\section{As dimensões pública e doméstica da hospitalidade: breves apontamentos}

Os estudos da hospitalidade pública e doméstica focam-se fortemente na teoria da dádiva como fato social total estruturador dos vínculos sociais entre indivíduos, grupos e sociedades. Marcel Mauss, grande pensador e fundador dessa perspectiva, aparece como a maior influência desta linha de estudos da hospitalidade, no entanto, é infrequente encontrar nos trabalhos dessa área referências às críticas e reformulações ao sistema da dádiva maussiano como as propostas por LéviStrauss, Bourdieu e Godelier (VILLA GONZALEZ, 2016). Esses autores aparecem sempre de maneira tímida nas pesquisas de hospitalidade, entretanto, quase todos estes estudiosos permeiam suas obras com exemplos do sistema da dádiva que se referem a momentos de hospitalidade como a recepção de estranhos com festas, banquetes - em muitas

1 JMJ Rio 2013. Orientações finais de hospedagem. [mensagem pessoal]. Mensagem recebida luvillagonzalez@gmail.com em 30 jul. 2013. 
ocasiões oferecidos aos deuses -, para exemplificar a lógica dar - receber - retribuir (MAUSS, 2013; GODELIER, 2001) muitas vezes inseridos em contextos rituais religiosos.

As relações entre hospitalidade e religião sempre foram bastante fortes e evidentes. Como o objeto deste estudo é um evento religioso, esta associação não poderia deixar de ser mencionada. Todos os grandes sistemas religiosos mundiais recomendam a prática da hospitalidade, tais quais 0 cristianismo, o judaísmo, o islamismo, o hinduísmo, o budismo, o taoísmo, entre outros (Coleman; Elsner, 1995; Komter; Leer, 2012; O'Gorman, 2010). Receber o estranho na própria casa é na maioria das religiões uma forma de se receber o próprio sagrado, e, consequentemente, bênçãos. Boff (2005) e O'Gorman (2010) mencionam que na Bíblia, Deus é apresentado como anfitrião e/ou hóspede frequentemente como em Matheus, (A Bíblia, 25, 3237), Genesis (A Bíblia, 18, 1-3; 19, 15-17) entre outras passagens.

Receber o estranho em casa pode ser assim considerado um ato de solidariedade e de troca com o próprio sagrado (VILLA GONZALEZ, 2016). Seguindo esta lógica, o espaço doméstico é aquele que vem à mente primeiramente quando pensamos no ato de acolher e integrar o outro. Contudo, esta prática tem seus custos e pode ser um tanto atribulada. Em uma cidade como o Rio de Janeiro, conhecida pela insegurança, colocar desconhecidos dentro do próprio lar pode ser ainda mais vivenciado como ato desafiador e arriscado que ganha um significado mais profundo de fé e confiança no próximo ou em Deus especialmente por esse risco ser assumido para apoiar um evento religioso. A generosidade cristã pode ser outro valor religioso relevante que se imprime a essa atitude dos anfitriões cariocas que materializaram 0 conceito de hospitalidade doméstica: as relações estabelecidas entre anfitriões e hóspedes dentro do espaço do lar (CAMARGO, 2004).

Receber em casa implica uma série de rituais e sacrifícios. Há que se saber receber, acomodar, alimentar, hospedar e entreter o hóspede o que exige tempo, dinheiro e dedicação (CAMARGO, 2004). Para quem é recebido, o ritual também pode apresentar desafios: é preciso adaptar-se às regras da casa acolhedora, evitar palavras, gestos e atos que podem ser ofensivos aos anfitriões e aceitar uma situação de dívida temporária diante destes até que se retribua o acolhimento em momento oportuno. As situações em que mal-entendidos e conflitos podem emergir são numerosas neste contexto. Entretanto, para jovens estrangeiros que pretendiam participar de um evento religioso como a JMJ Rio 2013 em um país famoso por sua violência, ser acolhido na casa de um "irmão de fé" pareceu uma alternativa viável tanto em termos de segurança quanto de economia.

Ao incentivar a hospitalidade doméstica, a Igreja Católica pretendia não apenas viabilizar financeiramente a viagem dos participantes, mas também estimular a relação entre católicos locais e de outras partes do Brasil e do mundo, o que segundo Villa Gonzalez (2016), deu ao evento um caráter coletivo que reforçou enormemente a identidade e pertença católicas aos participantes tanto para anfitriões quanto para hóspedes. Neste sentido, pode-se perceber o caráter agregador que a hospitalidade dentro do lar pode promover entre os diferentes sujeitos sociais.

Como ocorre em todos grande eventos sociais, a hospitalidade pública também foi bastante requisitada antes e durante a JMJ Rio 2013. A cidade como lugar hospitaleiro é objeto de estudo da "hospitalidade pública". Pessoas são recebidas em ambientes domésticos, mas, em um momento anterior, esse acolhimento ocorre em países, cidades e, consequentemente, espaços públicos como aeroportos, rodoviárias e postos de imigração. A responsabilidade da hospitalidade pública sai das mãos dos organizadores do evento e seria de maior responsabilidade do estado ou governo e da esfera pública em geral.

$\mathrm{Na}$ Antiguidade, a hospitalidade clássica era aquela que se voltava a satisfazer todas as necessidades básicas e de segurança das pessoas em movimento, incluindo-se aí suas demandas emocionais (GRINOVER, 2009). Nas sociedades 
modernas contemporâneas, a interpretação "clássica" de hospitalidade já não se aplica (GRINOVER, 2009). Entretanto, prover estruturas básicas para todos os tipos de visitantes é ainda uma faceta essencial para tornar os espaços urbanos locais estimuladores das trocas humanas de qualquer natureza, não obstante os aspectos legais, jurídicos, políticos e econômicos a que essas relações estão submetidas.

Para Degen (2008, p. 23), a hospitalidade pública acontece, principalmente, em espaços públicos onde nós aprendemos a lidar com estranhos. O conceito de estranho é central nos estudos de hospitalidade e peregrinação. É o estranho que afere nossa solidariedade, fraternidade e, no caso de indivíduos religiosos, como estes vivem os preceitos de seus credos. Os grandes sistemas religiosos mundiais recomendam que o estranho seja tratado como Deus, uma vez que esse sujeito pode efetivamente ser esse importante personagem e trazer bênçãos a todos (BOFF, 2005; O'GORMAN, 2010).

Lashley (2015) acredita que a hospitalidade é parte importante das esferas políticas e econômicas em âmbito local que colaboram para manter a coesão social. Para Grinover (2009), a hospitalidade em espaços públicos é característica essencial para as cidades que procuram se desenvolver, ofertando qualidade de vida a moradores e visitantes. Pode ser também uma forma de controle social e de opressão para aqueles que chegam, bem como instrumento de incentivo para trocas culturais e econômicas (BELL, 2012; LYNCH et al., 2011). Dessa maneira, fazer com que aquele "que vem" sinta-se confortável e seguro é essencial para que as cidades atinjam seus potenciais.

Lashley (2000) e O'Gorman (2010) defendem que a hospitalidade, em uma compreensão ampla, incluindo os espaços urbanos, deve ser compreendida em suas dimensões doméstica, cívica e comercial. Para isso, Bell (2007) e Lugosi et al. (2010) acreditam que uma cidade que busca prover facilidades públicas e serviços como um sistema de transportes abrangente, postos de informações e estabelecimentos de alimentação podem ser consideradas hospitaleiras. No entendimento de Lashley (2000), a hospitalidade pública ou "social" pode ser interpretada como as relações sociais que acontecem em espaços privados ou comerciais. Deste modo, os aspectos comerciais da hospitalidade são muito significativos para tornar a cidade um ambiente hospitaleiro, sendo importante olhar para esses serviços pagos como um "pacote" que afeta diretamente as esferas cívica e pública das cidades, não fazendo sentido para Bell (2007) separar as dimensões filosófica e gerencial desse fenômeno. De acordo com Bell (2007, p.6):

[...] the ways of relating that are practised in bars, cafés, restaurants, clubs and pubs should be seen as potentially productive of an ethics of conviviality that revitalizes urban living. The encounters in those spaces should, therefore, be reinstalled in discussions of the ethics and politics of hospitality $[\ldots]^{2}$

Seguindo esse raciocínio, Bell considera que "comer e beber" são ações sociais com significados muito mais profundos que aqueles que vêm a nossa mente em um primeiro momento, posto que são momentos fundamentais da vida social e de lazer das pessoas, podendo alterar completamente a experiência que estas têm de uma cidade e o significado que darão. Portanto, a experiência em restaurantes e bares pode, por exemplo, contribuir enormemente para a regeneração e melhoria da imagem desses espaços urbanos.

A JMJ Rio 2013 demandou da cidade do Rio de Janeiro não apenas sua estrutura urbana alterando a rotina de todos os habitantes da cidade, mas também solicitou que parte de sua população abrisse suas casas para receber os peregrinos. Entender como estes peregrinos perceberam essas ações e se sentiram em relação a isto foi o norte das perguntas relativas a hospitalidade feitas em um survey durante a JMJ Rio 2013 que serão descritos na seção a seguir.

\footnotetext{
${ }^{2}$ [...] as formas de relação/interação que são praticadas em bares, cafés, restaurantes, clubes e pubs deveriam ser vistas como potencialmente produtoras de uma ética de sociabilidade que revitaliza a vida urbana. Os encontros nestes espaços devem, portanto, ser reintroduzidos nas discussões da ética e da hospitalidade pública [...] (Traduzido pelos autores, 2015).
} 


\section{Metodologia}

Esta pesquisa possui caráter quanti-qualitativo e natureza exploratória. Os dados apresentados neste trabalho são oriundos de uma pesquisa de doutorado sobre a JMJ Rio 2013 e de um survey realizado no projeto de pesquisa "As novas configurações da religião no século $\mathrm{XXI}$ : um inventário sobre jovens participantes em eventos religiosos" organizado por Cecília Mariz (UERJ) e Paulo Gracino Junior (IUPERJ). Os questionários eram compostos por 39 questões que abarcavam temas como o perfil social dos participantes da JMJ Rio 2013, hábitos e crenças religiosos, etc. A temática da hospitalidade foi abordada em 6 perguntas nas quais este artigo se baseia. Foram aplicados 550 questionários em português, inglês e espanhol com participantes estrangeiros inscritos no evento. A amostra foi calculada e os questionários distribuídos a partir dos números divulgados pela Igreja Católica que afirmou ter 209 mil inscritos na JMJ Rio 2013 de 175 países, sendo os mais frequentes: Argentina, Estados Unidos, Chile, Itália, Venezuela, França, Paraguai, Peru e México (CNBB, 2013).

Além disso, apresenta-se falas de peregrinos estrangeiros coletadas a partir de entrevistas semiestruturadas realizadas por Villa Gonzalez (2016) como parte dos procedimentos metodológicos da tese "Estar no mundo, sem ser do mundo: alguns casos da JMJ Rio 2013" defendida no ano de 2016. Estas entrevistas também foram realizadas durante os 6 dias do evento sendo posteriormente transcritas e analisadas.

A partir desses dados, procurou-se captar as esferas da hospitalidade - doméstica e pública -, envolvidas na realização da JMJ Rio 2013 por meio de questões que abordam a opinião dos peregrinos a respeito dos meios de transportes, dos alojamentos públicos e domésticos, serviços de alimentação credenciados pela JMJ e segurança pública.
4 De braços abertos: a percepção dos participantes estrangeiros da JMJ Rio 2013 sobre a hospitalidade pública e doméstica do Rio de Janeiro

Iniciando a apresentação dos dados deste trabalho, detalha-se o perfil social dos participantes estrangeiros da JMJ Rio 2013. Segundo o survey de Mariz e Gracino Junior (2013), a maioria dos peregrinos de outros países era composta por homens (51,5\%), tinha entre 21 e 25 anos em 30,7\% dos casos, 18 a 20 anos entre $26,5 \%$ dos entrevistados e 16 e 17 anos entre 17,8\%. A maioria dos estrangeiros estava estudando na universidade ou possuía ensino superior completo (61,8\%), $13,1 \%$ ensino médio completo e $28,5 \%$ ensino médio incompleto. Quase a totalidade dos entrevistados $(94,2 \%)$ declarou ser solteira assim como $94,2 \%$ se declarou católica, o que não é de estranhar levando em conta a idade dos pesquisados e que o públicoalvo do evento eram jovens até 30 anos.

Como mostrado acima, a maioria dos peregrinos estrangeiros declarou ter até 25 anos de idade (MARIZ; GRACINO JR. 2013), portanto não parece surpresa que também a maioria $(81,6 \%)$ dos estrangeiros tenha vindo ao evento em grupos ligados a suas paróquias de origem ou aos movimentos religiosos dos quais participa. Do total de estrangeiros entrevistados, 47,1\% veio a JMJ Rio 2013 em grupos ligados a suas paróquias em seus países de origem e $34,5 \%$ por meio de movimentos jovens católicos tais quais o movimento Neocatumenal, Opus Dei, Focolares, entre outros. A organização da JMJ Rio 2013 incentiva a inscrição no evento por meio de grupos (VILLA GONZALEZ, 2016) para facilitar o planejamento do evento e a distribuição dos participantes por língua em diferentes partes da cidade. Durante as manhãs da JMJ, ocorriam as catequeses que se caracterizam por serem momentos de evangelização. Para melhor integrar os peregrinos estrangeiros, essas catequeses foram oferecidas em 25 línguas diferentes e para tal a Igreja dividiu a cidade em "áreas linguísticas" e assim a inscrição de peregrinos por grupos facilitava essa 
distribuição. O oferecimento de 25 idiomas durante o evento demostra de forma clara que havia entre os organizadores a preocupação de bem receber $\mathrm{e}$ agregar os participantes estrangeiros ao evento, o que pode ser considerado um gesto de hospitalidade pública no contexto pesquisado.

Era comum que os grupos solicitassem à organização do evento que seus membros fossem todos hospedados juntos em alguma escola ou outro espaço que tivesse capacidade de receber a todos dos grupos sem que ocorresse uma "separação". Essa solicitação era atendida sempre que possível e quando não havia possibilidade para tal, o setor de hospedagem da JMJ Rio 2013 alocava os diferentes membros de um mesmo grupo de peregrinos em casas de famílias geograficamente próximas, minimizando a sensação de desmembramento entre os peregrinos (VILLA GONZALEZ, 2016). Essa postura da organização era tida como uma atitude hospitaleira e foi entendida como tal pelos peregrinos entrevistados (VILLA GONZALEZ, 2016). Os dados a seguir corroboram estas análises.

Adentrando as questões mais ligadas ao tema deste trabalho, apresenta-se os dados relativos aos locais de hospedagem que os estrangeiros inscritos na JMJ Rio 2013 se acomodaram. A maioria absoluta escolheu se hospedar em casas de família e ou espaços como escolas, clubes, entre outros, oferecidos pela organização do evento em detrimento de opções não oferecidas pela JMJ Rio 2013: 82,5\%. Dos que não optaram pela hospedagem da JMJ, $4,7 \%$ hospedaram-se em hotéis ou outros estabelecimentos de hospitalidade comercial, 1,8\% em casa de familiares, 0,4\% em casa de amigos. Havia ainda 8,2\% que marcaram a opção "outros" (MARIZ; GRACINO Jr., 2013) que segundo os entrevistados eram espaços alugados por seus grupos para se alojarem, porém sem a intermediação da organização da JMJ Rio 2013 (VILLA GONZALEZ, 2016).

Em relação a como os entrevistados estrangeiros se sentiram acolhidos em seus meios de hospedagem, fossem estes domésticos ou em alojamentos escolas/ginásios/outros temos que:
$71,4 \%$ se sentiram "muito bem acolhido"; $23,8 \%$ "bem acolhido"; 1,8\% "indiferente"; 1,8 "mal acolhido";0,2 "muito mal acolhido" e 1,1\% "não respondeu" (MARIZ; GRACINO JUNIOR, 2013). Nas entrevistas semiestruturadas, registram-se alguns depoimentos sobre estas percepções:

[...] They were great (a família de acolhida). They gave us breakfast every morning even though they didn't have to. The organization could have been better, there weren't enough toilets. The subway and buses were good [...] (Jessica, peregrina, 17 anos, EUA).

[...] cada família em função daquilo que tinha, ofereceu o que tinha, sem olhar gastos, sem olhar cor, raça nada, somente a fé, o amor e a união [...] (Mara, peregrina,42 anos, Angola).

[...] Na família do Rio a experiência foi muito boa porque eles nos receberam em uma situação difícil, porque receber 15 pessoas não é fácil, eles se preocupavam com tudo que precisávamos, nos deram muito carinho, nos deram comida [...] era uma família muito especial, essa experiência me fortaleceu muito como cristã, católica e minha pertença na Igreja. (Mariana, peregrina,16 anos Colômbia).

Esses dados podem revelar que a acomodação em casas de família potencializou o sentimento de pertencimento a uma comunidade, a um grupo, sobretudo, quando se é recebido por alguém estranho que compartilha os mesmos símbolos, valores e crenças em um país diferente. A articulação da Igreja, para que isso fosse possível conectar peregrino e anfitrião - também pode ter reforçado essa sensação de comunhão e de identidade como relatado anteriormente. Russo (2012) afirma que o ambiente doméstico e, consequentemente, a hospitalidade doméstica propiciam maior intimidade, cuidado e segurança em um mundo em que relações líquidas (BAUMAN, 2001), sem comprometimento, são cada vez mais comuns. Dessa maneira, o acolhimento em um lar recuperaria algumas características buscadas atualmente por muitos que se sentem perdidos nesse contexto de modernidade líquida, o mesmo motivo que os leva a procurar uma religião. Fortaleceu-se assim, a identidade individual e coletiva católica, tanto 
para o hóspedes quanto para os anfitriões (VILLA GONZALEZ, 2016).

Já em relação à cidade do Rio de Janeiro como local de acolhimento, temos a seguinte avaliação: $63,1 \%$ dos entrevistados se sentiram "muito satisfeito" com a cidade; 32,5\% "satisfeito"; $1,1 \%$ "indiferente"; $1,6 \%$ "insatisfeito"; $0,7 \%$ "muito insatisfeito" e 0,9\% "não respondeu" (MARIZ; GRACINO Jr, 2013). Ao contrário do ocorrido em relação à hospitalidade doméstica seja nos lares dos cariocas ou nas escolas/ginásios e outros espaços de alojamento, o Rio de Janeiro não foi tão bem avaliado pelos entrevistados. As reclamações em relação às filas para a compra de alimentos, uso dos banheiros, tempo de deslocamento foram frequentes, sobretudo, nas entrevistas qualitativas realizadas:

[...] Filas, filas e mais filas, para comer, para o ônibus, para tudo [...] (Gisella, peregrina, 24 anos, Colômbia).

Bell (2007) e Lugosi et al. (2010) acreditam que uma cidade que busca providenciar serviços públicos e facilidades para seus "usuários" seria uma cidade hospitaleira. Desta forma, os transportes, a mobilidade urbana e os serviços de alimentação, mesmo que privados, são parte integrante da construção social do espaço público. Na visão de Lashley (2000), as relações sociais que acontecem nos espaços privados e comerciais podem ser definidas como "social hospitality" - o que englobaria tanto a hospitalidade doméstica quanto pública e comercial-, contribuindo para a percepção que os indivíduos têm sobre a cidade. Na pesquisa de Mariz e Gracino Jr. (2013), os peregrinos foram questionados sobre os transportes públicos do Rio de Janeiro e os serviços de alimentação aos quais eles tinham acesso, por meio de um cartão pré-pago, adquirido na inscrição.

No item referente aos transportes públicos $18,2 \%$ dos participantes estrangeiros disse estar "muito satisfeito"; 50\% "satisfeito" 6,7\% "indiferente"; 19,1\% "insatisfeito"; $3,8 \%$ "muito insatisfeito" e 2,2\% "não respondeu" (MARIZ; GRACINO JR. 2013). As reclamações relativas a esse quesito estiveram presentes em boa parte das falas dos entrevistados, porém foi possível perceber uma oscilação entre os peregrinos que compreendiam a situação de atrasos e filas, dentro da regularidade em um evento de grande magnitude, de outros que consideravam que esse fato era causado pela falta de organização como, por exemplo, a pane de duas horas do metrô do Rio de Janeiro no dia 23-07-2013, prejudicando fortemente a experiência da JMJ para os peregrinos, no primeiro dia do evento. O nível de insatisfação neste item foi o mais alto entre todos os avalizados na pesquisa:

[...] Acho que os transportes são bons. Por exemplo, a cidade onde vivo, só tem metrô e ônibus, Medillin (Colômbia) [...] O Rio de Janeiro tem metrô, trem e vias integradas, tem muita capacidade de transporte, mas para a quantidade de gente tão elevada, o transporte "colapsou", penso que as jornadas futuras devem ter um limite de pessoas [...] (Mariana, peregrina, 16 anos, Colômbia).

[...] Tudo "colapsa". O metro, o ônibus, o trem. Muita gente. No $1^{\circ}$ dia, no metrô, foi uma loucura. [...] (Damian, peregrino,18 anos, Chile $)^{3}$.

Quanto aos serviços de alimentação, 29,8\% dos estrangeiros declararam estar "muito satisfeitos" com a oferta deste tipo de serviço, enquanto 53,3\% afirmaram estar "satisfeitos"; 6,2\% "indiferentes"; 8,2\% "insatisfeito"; $0,2 \%$ "muito insatisfeito" e 2,4\% "não respondeu". De acordo com Bell (2007), comer e beber são importantes ações da vida social que moldam toda a experiência de se estar em uma cidade; e, para Mand e Cillers (2013), os serviços de comida e o espaço público têm importantes conexões que são evidentes no papel da vida pública das cidades, criando espaços públicos hospitaleiros, pois comer é uma necessidade e um prazer, individual e social, o que os dados apresentados parecem indicar.

Quando questionados sobre quais os itens de uma cartela com 12 opções foram os mais apreciados

\footnotetext{
${ }^{3}$ Esta fala refere-se ao colapso de duas horas do Metro do Rio de Janeiro no dia 23-07-2013, primeiro dia da JMJ. Ver: "Metro do Rio fica mais de duas horas parado por falta de energia". Jornal do Brasil de 23/07/2015. http://www.jb.com.br/rio/noticias/2013/07/23/metro-do-rio-ficamais-de-duas-horas-parado-por-falta-de-energia/
} 
no evento, os entrevistados responderam da seguinte maneira: 55,8\% escolheram a "hospitalidade carioca" com item mais apreciado; $42,4 \%$ optaram pelo "apelo religioso do evento"; "assistência ao peregrino" foi escolhido por 39,5\%; "segurança" por 26,2\%; "informações turísticas" por 21,5\%; "restaurantes" por 18\%; "organização" por 14\%; "hospedagem" por 12,9\%; "divulgação" por 7,6\% e 8,4\% por "opções de lazer". Aqueles que não responderam somaram 0,2\% e os que não optaram por nenhum item 0,7\%. As comparações entre as esferas privada e pública da hospitalidade tornaram-se bastante presentes nessa questão:

[...] para dizer a verdade em comparação a Madri, pelo tempo que já se sabia do evento, estava ruim, mas a acolhida compensa tudo, as pessoas acolhem bem a todo o mundo [...] (Giorgio, peregrino, 26 anos, Itália).

[...] não esperava que o brasileiro fosse tão carinhoso, amoroso e receptivo. Incrível. Muito obrigada a vocês todos [...] (Carlos, peregrino, 19 anos, Equador).

[...] Brazilians are not so bad as the media says. They are kind, they don't offer help first, but when they are asked to they are friendly and cool $[\ldots]^{4}$ (Cinta, 25 anos, Indonesia).

Em algumas entrevistas qualitativas, os peregrinos estrangeiros relataram que pessoas ofereceram suas casas em Copacabana - local onde os eventos liderados pelo Papa aconteceram -, para que o banheiro fosse utilizado, ou que:

[...] quando a gente passa pelos brasileiros, eles sempre gritam "Chi, Chi, Chi, Lê, Lê, Lê". São muito receptivos, carinhosos conosco [...] (Damian, peregrino,18 anos, Chile).

Quando se comparam os dados quantitativos e qualitativos pode-se avaliar que houve uma separação por parte dos peregrinos da relação público/privado, dos aspectos de caráter infra estrutural e do pessoal. Uma colombiana relatou que, depois de uma experiência bem sucedida, em que

\footnotetext{
${ }^{4}$ [...] Brasileiros não são tão ruins assim como a mídia fala. Eles são gentis, eles não oferecem ajuda primeiramente, mas quando solicitados eles são muito amigáveis e legais [...] (Traduzido pela autora, 2015).
}

"houve muito intercâmbio cultural" e "compartilhamento de experiências" na semana missionária ${ }^{5}$ em Caraguatatuba/SP, onde ficou, na casa de uma família, ela ficou hospedada em um colégio no Rio de Janeiro, no qual a infraestrutura era muito precária, já que chovia dentro dos alojamentos, o local era frio e tudo lhe pareceu improvisado. Porém, após duas noites, um senhor brasileiro "apareceu" e convidou seu grupo de 15 pessoas para se hospedar na casa dele. Esse senhor realizou várias idas e vindas entre o alojamento e sua casa com seu carro particular, para levar toda à bagagem do grupo, e, segundo ela, esse tipo de situação "potencializou" sua experiência de JMJ. Os brasileiros e sua hospitalidade foram elogiados nas entrevistas, contudo, os transportes, a organização e os serviços de alimentação não obtiveram a mesma percepção como os números a seguir comprovam.

Indagados sobre os itens que menos apreciaram na JMJ, os estrangeiros escolheram as seguintes opções entre 12 possibilidades: 43,5\% não apreciaram a "organização" do evento; 25,6\% a "segurança"; "nenhum" item dentre os apresentados, $20,7 \%$; $12,5 \%$ os "restaurantes"; $8,7 \%$ as "informações turísticas"; 6,9\% "as opções de lazer"; 6,7\% "a divulgação"; "hospedagem", 6\%; "assistência ao peregrino", 4,2\%; "hospitalidade carioca", 1,8\%; "apelo religioso", 1,5\%; "outros", 1,1\% e "não respondeu”, 0,9\% (MARIZ; GRACINO JR, 2013).

O quesito "organização" foi o mais citado pelos respondentes que atribuíram os transtornos vivenciados durante a JMJ à falta de organização do evento. As reclamações sobre o posto de entrega dos "kits peregrinos" foram bastante presentes nas entrevistas qualitativas uma vez que a grande maioria reclamou deste local. O Centro de Distribuição de "kits peregrinos" foi montado no Sambódromo na região central do Rio de Janeiro. Havia também outro centro desses, porém em espaço menor e localizado em Santa Cruz. O planejamento inicial do evento sugeria que fossem instalados vários desses centros, em diversos pontos da cidade para distribuir o volume

\footnotetext{
${ }^{5}$ Evento realizado no período anterior ao da JMJ Rio 2013 em todo o Brasil para preparar os peregrinos para o evento.
} 
de pessoas concentradas em um só local e agilizar o atendimento. Porém, como os custos da JMJ ultrapassaram o esperado, esses pontos foram reduzidos a dois, incorrendo em tempo excessivo de espera e em falta de agilidade no atendimento. $O$ sistema informatizado da organização do evento também entrou em pane alguns dias antes da JMJ e durante o evento, o que tornou a situação ainda mais complexa, pois os peregrinos que deveriam ir aos centros de distribuição de "kits" apenas para retirálos, chegavam ao local, muitas vezes, sem a informação de onde seriam suas catequeses e os locais de hospedagem. Tais questões precisariam ser resolvidas nos "centros de atendimento", gerando ainda mais filas. Além disso não disponibilizaram aos peregrinos nem banheiros nem serviços de alimentação no entorno do Sambódromo. Todo esse cenário pode ter gerado uma primeira má impressão nos visitantes, uma vez que revelavam "falhas" na organização do evento (VILLA GONZALEZ, 2016).

Alguns dados indicam que os peregrinos que chegaram nos primeiros dias da JMJ tiveram uma percepção melhor desse serviço, pois ainda não estava chovendo ${ }^{6}$ na cidade do Rio de Janeiro, e o maior fluxo de participantes não tinha chegado à cidade. Para aqueles que chegaram entre o segundo e quarto dia do evento, as filas duraram até 7 horas, segundo alguns peregrinos, o que provocou 0 descontentamento de muitos deles.

\section{Considerações finais}

O objetivo deste trabalho era apresentar dados relativos a percepção de hospitalidade pública e doméstica dos estrangeiros participantes da JMJ Rio 2013. A pesquisa baseou-se em métodos qualitativos e quantitativos para a coleta de dados e os resultados revelam que a acolhida dos cariocas, principalmente em ambiente doméstico, foi bem avaliada pelos peregrinos estrangeiros. A atitude receptiva e os esforços para bem receber os participantes do evento demostrada pelos anfitriões cariocas em suas próprias casas parece ter causado boa impressão nos participantes de outros países da JMJ Rio 2013. Entretanto, os serviços de organização, transporte e segurança parecem ter prejudicado a experiência dos peregrinos, impedindo-os muitas vezes de chegarem as atividades das quais queriam participar e tornando o evento cansativo em muitas ocasiões. Conclui-se, portanto, que não necessariamente o bem receber doméstico espelha-se na boa acolhida pública. No entanto, acredita-se que quando estas esferas da hospitalidade - pública e doméstica - se equivalem e são bem planejadas e organizadas, a experiência dos visitantes pode ser potencializada trazendo benefícios posteriores ao todo social.

\section{Referências}

BAUMAN, Z. Modernidade líquida. Rio de Janeiro: Zahar, 2001.

BELL, D. The hospitable city: social relations in commercial spaces. Progress in Human Geography, v. 1, n. 31, 2007.

BELL, D. Hospitality is society. Hospitality \& Society, v. 1, n. 2, p. 137-152, 2012.

A BÍBLIA. Português. Ave Maria. São Paulo: Ed. Claretiana, 2008.

BOFF, L. Virtudes para um outro mundo possível: hospitalidade. v. I. Petrópolis: Vozes, 2005.

BRASIL. Ministério do Turismo. Pesquisa releva que turistas da JMJ querem voltar ao Brasil. Disponível em: <http://www.turismo.gov.br/turismo/noticias/tod as_noticias/20130801.html>. Acesso 2 ago. 2013.

CAMARGO, L. O. Hospitalidade. São Paulo: Aleph, 2004.

\footnotetext{
${ }^{6}$ Na maior parte da JMJ Rio 2013, uma chuva torrencial atingiu a cidade do Rio de Janeiro dificultando o cotidiano tanto dos anfitriões quanto dos hóspedes/peregrinos.
} 
COLEMAN, S.; ELSNER, J. Pilgrimage, past and present: sacred travel and sacred space in the world religions. London: British Museum Press, 1995.

\section{CONFEDERAÇÃO NACIONAL DOS BISPOS DO} BRASIL. Balanço final da JMJ Rio2013: público recorde de 3,7 milhões de pessoas em Copacabana. 2013. Disponível em < http://www.cnbb.org.br/index.php?option=com content\&view=article\&id=12522:balanco-finalda-jmj-rio2013-publico-recorde-de-37-milhoesde-pessoas-emcopacabana\&catid=251\&itemid=126>. Acesso em 01 set. 2013.

DEGEN, M. Sensing Cities: Regenerating Public Life in Barcelona and Manchester. London: Routledge, 2008.

DIÁRIO DE CAMPO. VILLA GONZALEZ, Luciana Thais Villa. [Org.]. Compilado de questionários, entrevistas, impressos de documentos online indexados utilizados na pesquisa/ Tese intitulada: Estar no mundo, sem ser do mundo: alguns casos da Jornada Mundial da Juventude (JMJ) Rio 2013.

GRINOVER, L. A hospitalidade na perspectiva do espaço. Revista Hospitalidade, v. I, n. 1, p. 416, 2009.

GODELIER, M. O engima do dom. Rio de Janeiro: Civilização Brasileira, 2001.

JMJ Rio 2013. Orientações finais de hospedagem. [mensagem pessoal]. Mensagem recebida por luvillagonzalez@gmail.com em 30 jul. 2013.

KOMTER, A.; LEER, V. M. Hospitality as a gift relationship: political refugees as guests in the private sphere. Hospitality \& Society, v. 2, n. 1, p. 7-23, 2012.
LASHLEY, C. Towards a theoretical understanding. In: LASHLEY, C.; MORRISON, A. (Ed.). In search of hospitality: theoretical perspectives and debates. Oxford: Butterworth-Heinemann, 2000.

- Hospitality and Hospitableness. Revista Hospitalidade, n. V.XII (special number), p. 7092, 2015.

LUGOSI, P et al. Hospitality, culture and regeneration: Urban decay, entrepreneurship and the "ruin" bars of Budapest'. Urban Studies, v. 14, n. 47, p. 3079-3101, 2010.

LYNCH, P. et al. Theorizing hospitality. Hospitality \& Society, v. 1, n. 1, p. 3-24, 2011.

MAND, H.; CILLIERS, S. Hospitable urban spaces and diversity. Hospitality \& Society, v. 3, n. 1, p. 211-228, 2013.

MARIZ, C. L; GRACINO Jr, P. As novas configurações da religião no século XXI: um inventário sobre jovens participantes em eventos religiosos. No prelo.

MAUSS, M. Ensaio sobre a dádiva: forma e razão da troca nas sociedades arcaicas. São Paulo: Cosac Naify, 2013.

O'GORMAN, K. D. The origins of hospitality and tourism. Oxford: Goodfellow Publishers Limited, 2010.

RUSSO, M. Home, domesticity and hospitality: A theoretical reflection. Hospitality \& Society, v. 2, n. 3, p. 309-320, 2012.

SINGLETON, A. The impact of World Youth Day on religious practice. Journal of Beliefs \& Values, v. 32, n. 1, p. 57-68, 2011. 
VILLA GONZALEZ, L.T. Estar no mundo, sem ser do mundo: alguns casos da Jornada Mundial da Juventude (JMJ) Rio 2013. 2016. 250 f. Tese. (Doutorado em Ciências Sociais) - CCS, Universidade do Estado do Rio de Janeiro,2016. 